Produto \& Produção, vol. 13 n. 1, p. 131-147 fev. 2012

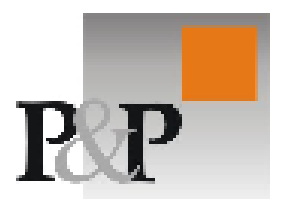

\begin{abstract}
Gestão de configurações e ramp-up de novos produtos: estudo de caso em uma empresa brasileira de base tecnológica
\end{abstract}

Recebido em 25/10/2011. Aceito em 11/02/2012.

Matheus de Aguiar Sillos

Departamento de Pesquisa e Desenvolvimento - Opto Eletrônica S/A

matheus.sillos@opto.com.br

Sanderson César Macêdo Barbalho

Departamento de Pesquisa e Desenvolvimento - Opto Eletrônica S/A

sanderson@opto.com.br

\title{
Junia Rojic
}

Departamento de Pesquisa e Desenvolvimento - Opto Eletrônica S/A

junia@opto.com.br

O artigo discute o conceito de ramp-up aplicado na gestão de configurações de produtos desenvolvidos por uma empresa brasileira de base tecnológica. $\mathrm{O}$ estudo parte da experiência na implantação de melhorias na gestão de configurações (GC) de produtos, realizadas por essa empresa de médio porte, fabricante de equipamentos médicos, localizada no interior do Estado de São Paulo. Foram levantados e analisados dados referentes de seis linhas de produtos da empresa, relacionando o número de alterações das configurações nos doze primeiros meses do lançamento dos produtos com uma análise de ramp-up dos mesmos. Observouse a viabilização do controle de ramp-up dos produtos pela sua gestão de configurações. Uma discussão acerca das características dessas curvas foi realizada, concluindo que a análise do ramp-up atrelado à gestão das configurações é uma ferramenta valiosa para a aplicação de melhoria contínua ao longo da fase de lançamento de novos produtos.

Palavras chave: desenvolvimento de produtos; gestão de configurações; ramp-up.

This paper discusses how the concept of ramp-up is applied to the product configuration management process in a Brazilian technology company. The study is focused on the experience in implementing improvements on configuration management, made by this medium-sized company - a manufacturer of medical equipments, located in the State of São Paulo. Data from six product lines of the company were collected and analyzed. It was listed the number of changes in the first twelve months after product launch based on a ramp-up analysis of them. The efectivity of the products' ramp-up control by means of their configuration change management was observed. A discussion about the characteristics of ramp-up 
curves was made, concluding that the analysis of ramp-up founded in a configuration change evaluation is a valuable tool of continuous improvements at the new product launch phases.

Keywords: product development, configuration management, ramp-up.

\section{INTRODUÇÃO}

O processo de desenvolvimento de produtos (PDP) é um importante processo de negócio responsável pela satisfação do consumidor nos usos e aplicações dos produtos, sendo uma competência requerida das empresas. As atividades do PDP atravessam diversas áreas funcionais da empresa seguindo uma cadeia de valor que tem início no levantamento dos requisitos dos clientes, passando pelo projeto do produto propriamente dito, pela transferência das especificações dos produtos para a área de manufatura e se estendendo ao acompanhamento do desempenho do produto de forma a avaliar seus resultados, assim como as oportunidades e necessidades de mudanças no produto. Logo, a excelência na gestão do PDP tem se tornado, um fator crítico no lançamento eficaz de novos produtos e na melhoria da qualidade dos produtos existentes.

Para empresas de base tecnológica, a capacidade de melhorar os produtos já existentes é um aspecto fundamental, a qual deve se pautar em processos robustos sob o ponto de vista dos pacotes de serviços entregues aos clientes e da gestão da configuração (GC) do produto. Rozenfeld et al (2006) afirmam que por mais que se apliquem novas técnicas de desenvolvimento de produtos, sempre acontecerão mudanças no produto, causadas por otimizações do projeto, processo, detecção de defeitos, reclamações, adaptação dos produtos a novas condições, redução de custos etc. Todas as mudanças efetuadas que resultam em atualizações das suas informações, sejam em desenhos, especificações de material, processos de fabricação etc., são conhecidas como mudanças de engenharia. Pode-se entender gestão de configurações como o controle de mudanças de engenharia, tornando possível incorporar melhorias e novas funcionalidades aos produtos sem perder 0 controle sobre a sua configuração.

Segundo Santos (1997) empresas de base tecnológica têm um importante papel no desenvolvimento social e econômico dos países menos desenvolvidos, pois permitem que se realizem inovações em produtos, estimulam o progresso da ciência e tecnologia, geram empregos qualificados e possibilitam a substituição da importação de determinados produtos. Por adotarem estratégias baseadas em nichos de mercado, essas empresas confiam na agilidade e competência de suas respostas às necessidades dos clientes como forma de se manterem competitivas.

\section{METODOLOGIA}

Este artigo apresenta o caso de uma empresa nacional de base tecnológica de médio porte, que incorporou, a partir de 2006, práticas de gestão de configurações ao longo de seu PDP. Apresenta-se neste artigo as curvas referentes à GC dos seguintes equipamentos produzidos pela empresa: equipamento de 
fotografia do fundo do olho, equipamentos de cauterização de lesões na retina com laser, equipamento para medição de acuidade visual, equipamento para tratamento de ceratonone e acessório para cirurgias de retina. $O$ estudo considerou doze meses a partir do lançamento de cada um desses produtos.

A metodologia empregada pode ser caracterizada como Estudo de Caso holístico. A unidade de análise é o ramp-up de produtos de alta tecnologia, analisada no setor de equipamentos médicos da empresa.

Primeiramente realizou-se a caracterização das práticas de gerenciamento aplicadas para os projetos do setor de equipamentos médicos. Em seguida deu-se a análise dos dados das mudanças de engenharia de cada equipamento citado anteriormente. Os resultados são discutidos nas considerações finais.

O trabalho foi desenvolvido mediante um processo de pesquisa-ação, conforme Thiolent (2006). Utilizou-se procedimentos de entrevistas com profissionais da empresa, observação direta e análise de documentos que registram as atividades realizadas em cadernos de campo.

\section{GESTÃO DE CONFIGURAÇÕES DO PRODUTO}

Para Clark e Fujimoto (1991), as fases do PDP são definidas em função dos resultados que geram, ou seja, das informações geradas por cada fase. Esses documentos representariam o conceito de "informações de valor". O conceito de "informação de valor", embora fortemente presente no trabalho desses autores não gerou análises e propostas que permitissem seu desdobramento no que seria, posteriormente, denominado "controle da configuração do produto" (CCP).

Segundo Rozenfeld et al (2006), configuração é definida como o conjunto de todas as informações relacionadas ao produto. Essas informações são aquelas resultantes do processo de desenvolvimento de produtos. A gestão da configuração organiza e controla de forma uniforme e sistemática, as descrições do produto envolvendo sua identificação, controle e auditoria.

Dentre os autores clássicos na área de gestão do PDP, nenhum aborda especificamente a gestão da configuração. O mais próximo é o trabalho de Nonaka e Takeushi (1995) com a introdução questão da gestão do conhecimento, a qual faz uso do controle de configurações e o fomenta, na medida em que gera lições aprendidas ao longo dos novos projetos.

Um fator importante para a consolidação do conhecimento sobre gestão de configurações dos produtos é a área de gestão de projeto e desenvolvimento presente nas normas da série ISO 9000, a qual prescreve a gestão de documentos e de configurações, através de seu capítulo 4, como ferramenta para o gerenciamento do sistema de gestão da qualidade, conforme consta em Barbalho (2006).

O padrão estabelecido pelo PMI para a gestão de projetos em geral, incluindo projetos de novos produtos, indica o controle de configurações como elementochave para a gestão da integração do projeto, atividade fundamental do gerente de projetos. O project management body of knowledge (PMBOK) diferencia a configuração do produto e a configuração do projeto, ambas ocorrendo ao longo do desenvolvimento de produtos, confome PMI (2005).

Samaras e Czerwinski (1971) consideram que a gestão de configurações tem por base os seguintes componentes: (1) identificação da configuração: documentação técnica que identifica e descreve a configuração do produto aprovado 
ao longo das atividades de projeto, desenvolvimento, teste e produção;(2) controle da configuração: sistemática de avaliação, coordenação, aprovação ou rejeição de uma proposta de mudança para o projeto, e construção de um "item de configuração" cuja configuração foi formalmente aprovada pela empresa, cliente, ou ambos; e (3) verificação da configuração: registrar e reportar as descrições dos itens da configuração, além de verificar a integridade dos dados autorizados do projeto com a configuração fabricada e testada.

Watts (2000) enfatiza alguns processos habilitadores da GC, agindo de maneira conjunta e na intensidade definida pelo gerente responsável. Os processos seriam três: processo de estruturação do produto, processo de criação e liberação da documentação e do produto, e processo de controle das mudanças de engenharia. Todos seriam executados de maneira paralela e abrangem todo o ciclo de vida do produto.

\section{RAMP-UP}

Os ciclos de vida dos produtos cada vez mais curtos e a rápida obsolescência dos mesmos incentivam a entrada de novos produtos no mercado cada vez mais rápida. Como conseqüência, as empresas têm se concentrado em melhorar os processos de desenvolvimento de novos produtos para obter os benefícios da entrada mais cedo no mercado. Acadêmicos têm analisado esta questão, examinando as implicações das métricas de desenvolvimento de novo produtos (por exemplo, time-to-market e tempo de ramp-up) e identificando métodos (por exemplo, planejamento agregado, equipes multifuncionais, engenharia simultânea) que as empresas podem adotar para melhorar seu processo de desenvolvimento de novos produtos (CARRILO; FRANZA, 2006).

Segundo Haller et al (2003), ramp-up é o processo de aumento da taxa de produção de uma fábrica, do primeiro lote até o volume final de produção. Pode-se entender por ramp-up, ou rampa de produção, como o termo utilizado para designar as etapas iniciais do processo de fabricação das primeiras unidades dos produtos a serem comercializados, logo após a conclusão das atividades de projeto.

Da perspectiva da manufatura, o lançamento de produto pode causar um rompimento devido ao processo de mudanças ou processo de adição, resultando na desaceleração da linha de produção e/ou na perda de qualidade do produto. Durante - lançamento da fabricação, a instalação ou diminui a taxa de fabricação do novo produto para evitar encontrar muitos problemas no início, ou mantém a taxa constante, mas sofre perda de rendimento. Este período de transição pode durar de poucas semanas a meses. Dependendo do processo de solução de problemas durante a fabricação, a instalação aumentará sua taxa de produção até sua capacidade total. Este processo é chamado de ramp-up de manufatura (AKAMPHON, 2008).

Um dos principais estudos relacionado com o ramp-up de produtos após as atividades de projeto é a análise de Clark e Fujimoto (1991). Segundo os autores, velocidade, eficiência e representatividade dos protótipos e de seus testes são essenciais na identificação de problemas de engenharia e na antecipada melhoria da qualidade do design, antes que mudanças de engenharia se tornem caras. $\mathrm{Na}$ ausência de protótipos que reflitam a verdadeira intenção do produto, sem o efetivo teste, e com fracas ligações entre protótipo e produção comercial, muitos problemas 
no projeto e produção são detectados somente durante o lote piloto ou mesmo durante o ramp-up da produção. Portanto, o resultado é uma maior quantidade de mudanças de engenharia realizadas tardiamente no projeto, o que sobe o custo, atrasa o início da produção e a introdução no mercado, e leva a uma grande quantidade de problemas de qualidade em campo, reclamações e recalls. A reputação do produto e o desempenho dos vendedores sofrem, implicando também em aumentos do tempo de parada na planta produtiva, como consequência da necessidade de consertar problemas na produção.

Carrilo e Franza (2006) afirmam que o conhecimento inicial relacionado ao projeto, a eficiência dos investimentos em conhecimento de projeto e o valor estratégico deste conhecimento para competir em horizontes de planejamento futuro são importantes fatores para o tempo de ramp-up.

Mesmo os executivos de grandes companhias pensam em DP como a criação de características intangíveis, mas alertam que focar no processo cognitivo é negligenciar a real contribuição da manufatura. A habilidade de fazer rápido e eficientemente é uma fonte crítica de vantagens do DP. Capacidade de fabricação é obviamente importante na produção comercial. Na discussão sobre a relação entre a capacidade de fabricação e o desempenho do DP, pode-se elucidar as seguintes atividades: fabricação de protótipos e produção pré-comercial durante o lote piloto e o ramp-up (CLARK; FUJIMOTO, 1991).

Segundo Haller et al (2003), a fase de ramp-up é a mais difícil e desafiadora. Por um lado, os preços dos produtos são mais elevados no início do ciclo de vida. Por outro, essa fase pode conter já uma parte considerável de todo ciclo de vida de vários produtos, devido ao encurtamento desses ciclos e substituições de produtos cada vez mais rápidas.

O início da manufatura do produto da produção, na indústria automotiva, ocorre em média três meses antes do início das vendas, segundo Clark e Fujimoto (1991), o que permite abastecer os canais de distribuição. Assim como para os lotes piloto, existem diferentes estágios para a fabricação de novos modelos. O início da manufatura pode se dar em uma nova planta, ou pode substituir a produção de um outro modelo abruptamente ou gradualmente, conforme pode-se visualizar na Figura 1. Essas diferentes abordagens para o ramp-up expõem a companhia a diferentes riscos e por isso requerem diferentes capacidades. Como essas capacidades são usadas no ramp-up e no lote piloto, acabam afetando o tempo para mercado, o nível de investimento e a qualidade do feedback para a engenharia.

Uma corrida do lote piloto de sucesso é seguida do ramp-up, o início da produção comercial, que começa lentamente e gradualmente acelera até a produção total. O propósito do lote piloto e do ramp-up é encontrar e resolver problemas que não foram detectados nos protótipos e nos testes. Como eles ocorrem no final do PDP, logo antes das vendas comerciais, lotes pilotos e ramp-up podem ter um impacto crítico na percepção do mercado e sucesso econômico (CLARK; FUJIMOTO, 1991).

Akamphon (2008) afirma que durante o desenvolvimento de produtos, a equipe de desenvolvimento trabalha no conceito do produto e nos parâmetros do projeto, ao mesmo tempo eliminando problemas potenciais decorrentes do projeto. A equipe busca resolver todos os problemas do projeto antes de submeter o projeto à fabricação. Entretanto, devido à pressão do tempo e limitações de recursos, a equipe nunca é capaz de eliminar todos os problemas, aparecendo problemas apenas na manufatura. 


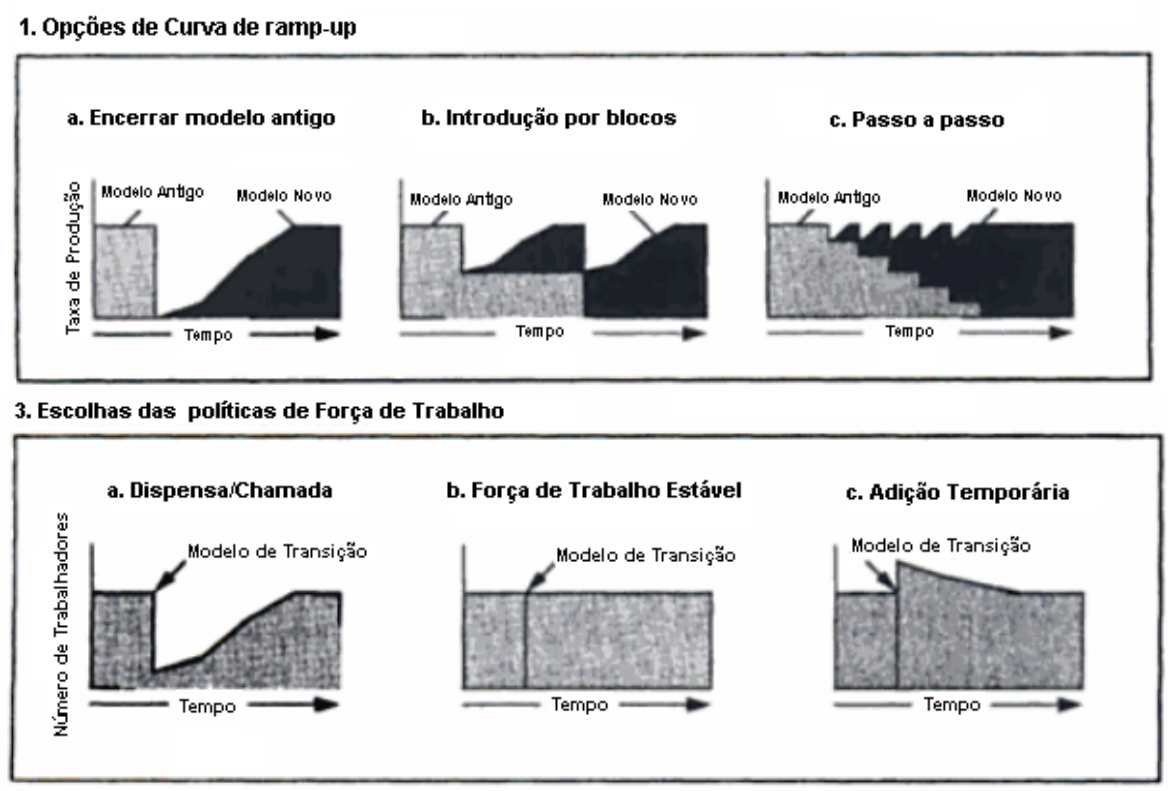

Figura 1 - Início da manufatura do produto e suas características. Fonte: Livro Clark \& Fujimoto (1991)

Esses defeitos afetam os erros encontrados em manufatura e a qualidade dos produtos finais. Os erros de manufatura aumentam os custos, enquanto a qualidade do produto final influencia a reputação da empresa e a demanda pelos produtos.

Carrilo e Franza (2006) afirmam que o ramp-up ótimo ocorre quando a capacidade de produção acumulada atinge o pico de demanda previsto para o novo produto.

Segundo Clark e Fujimoto (1991), a aceleração gradual da escala de produção reflete na chamada curva de ramp-up. O tempo para plena produção varia de 1 a 6 meses, enquanto o tempo alvo para qualidade e produtividade varia de 1 mês a 1 ano. A produção efetiva do ramp-up depende fortemente da capacidade de manufatura, conciliando com as escolhas feitas sobre a forma geral da curva de ramp-up, sobre operações padrões e força de trabalho, conforme mostra a Figura 1 acima. Diferentes escolhas nas maneiras de conduzir o início da manufatura do produto estão ligadas a diferentes capacidades de manufatura. Em termos de rampup existem 3 métodos:

O primeiro é simples e evita a produção misturada por causa do risco de grandes produções e perdas de vendas. Para minimizar as perdas requer uma curva de ramp-up com grande inclinação. O segundo prevê uma diminuição do uso do antigo modelo pela metade e implanta na outra metade o novo modelo. O terceiro faz a mudança do velho para o novo modelo lentamente, no chamado passo-apasso, tirando gradualmente o antigo e implantando o novo em seu lugar. A maneira que a força de trabalho se ajusta determina a produtividade e o custo durante o ramp-up. Essas três maneiras de conduzir o início da manufatura do produto são mostradas na Figura 1. As dificuldades das mudanças impostas por cada uma das estratégias, no primeiro método de encerrar o modelo antigo e aumentar o ramp-up rapidamente enquanto procura diminuir a confusão e atingir uma alta qualidade, no segundo e no terceiro métodos de controlar a complexidade da distribuição de materiais e da programação da produção enquanto continuam a alcançar a qualidade e o custo alvos tanto para o novo quanto para o antigo modelo, são 
influenciadas pela escolha dos padrões de operações e dos ajustes na força de trabalho.

Clark e Fujimoto (1991) mostram que em termos de ramp-up, por exemplo, EUA e Europa utilizam o primeiro método. Já as empresas japonesas utilizam a segunda ou terceira opção de início da manufatura do produto e ramp-up da produção. Os japoneses usam um modelo com aumento temporário na força de trabalho, enquanto os europeus dependem de ajustes na velocidade da linha e consequentemente na força de trabalho. No modelo japonês a linha e as horas de operação são estáveis. Os trabalhadores adicionais absorvem o impacto dos declínios na produtividade, assim o velho e o novo modelo são produzidos. Enquanto o ramp-up prossegue, os trabalhadores extras são retirados. No modelo americano, a linha começa devagar e aos poucos sao adicionados habilidosos e experientes trabalhadores para lidar com um amplo leque de tarefas. Quando a velocidade da linha aumenta, novos trabalhadores são adicionados e as tarefas redistribuídas. Ao longo do tempo a força de trabalho é trazida para completar a linha e esta alcança o nível de produtividade planejado. O paradigma americano é baseado em resolver o conflito entre aprender e produzir separando modelos novos dos já existentes e usando um pequeno número de mais habilidosos e experientes trabalhadores nos primeiros estágios do ramp-up. Isso faz com que a produção inicial fique menos complexa em termos de manuseamento de materiais e envolvimento da força de trabalho, mas os resultados são menos contínuos e estáveis. O modelo japonês enfatiza a continuidade e estabilidade das condições de operação e das atribuições dos funcionários de linha o que deve dar suporte ao aprendizado. A capacidade superior da manufatura, que é necessaria por causa da complexidade associada a esse modelo, tende a ser característica das melhores empresas japonesas. O controle de todo o processo, assim como a continuidade e flexibilidade inerentes ao modelo japonês, ajuda a minimizar confusões no chão de fábrica e aumenta o aprendizado durante o ramp-up.

Tabela 1 - Características e Paradigmas. Fonte: Clark \& Fujimoto (1991)

\begin{tabular}{|c|c|c|c|c|}
\hline \multicolumn{5}{|c|}{ Características e Paradigmas das Fabricações dos Protótipos } \\
\hline $\begin{array}{l}\text { Característi } \\
\text { ca / Região }\end{array}$ & Japão & EUA & $\begin{array}{c}\text { Europa } \\
\text { (grandes } \\
\text { produtores } \\
\text { ) }\end{array}$ & $\begin{array}{c}\text { Europa } \\
\text { (alta- } \\
\text { qualidade) }\end{array}$ \\
\hline Lead Time & $\begin{array}{l}\text { curto (6 } \\
\text { meses) }\end{array}$ & $\begin{array}{c}\text { longo (12 } \\
\text { meses) }\end{array}$ & longo & $\begin{array}{c}\text { longo (11 } \\
\text { meses) }\end{array}$ \\
\hline Quantidade & média (38) & média (34) & média (37) & alta (54) \\
\hline $\begin{array}{c}\text { Custo } \\
\text { Unitário }\end{array}$ & médio & médio & médio & alto \\
\hline $\begin{array}{l}\text { Representat } \\
\text { ividade e } \\
\text { conformida } \\
\text { de do } \\
\text { design }\end{array}$ & $\begin{array}{l}\text { razoavelmen } \\
\text { te alta } \\
\text { representativ } \\
\text { idade e } \\
\text { conformidad } \\
\text { e }\end{array}$ & $\begin{array}{c}\text { as vezes } \\
\text { baixa em } \\
\text { ambas as } \\
\text { dimensões }\end{array}$ & $\begin{array}{c}\text { razoavelme } \\
\text { nte elevado } \\
\text { em ambas } \\
\text { as } \\
\text { dimensões }\end{array}$ & $\begin{array}{c}\text { muito alta } \\
\text { em ambas } \\
\text { as } \\
\text { dimensões }\end{array}$ \\
\hline $\begin{array}{c}\text { Fornecedor } \\
\text { es das } \\
\text { partes dos } \\
\text { protótipos }\end{array}$ & $\begin{array}{l}\text { maior parte } \\
\text { produção } \\
\text { dos } \\
\text { fornecedores }\end{array}$ & $\begin{array}{l}\text { somente } \\
\text { pecas } \\
\text { especiais }\end{array}$ & misturado & misturado \\
\hline
\end{tabular}




\begin{tabular}{|c|c|c|c|c|}
\hline \multirow{4}{*}{ Paradigma } & protótipo & protótipo & divisão & \\
& como & como uma & entre o & protótipo \\
& detector de & ferramenta & modelo & como \\
& problemas & para & mestre e o & modelo \\
& (ambos o & melhorar o & teste do & mestre \\
& processo e o & design do & design do & \\
& produto) & produto & produto & \\
\hline
\end{tabular}

Clark e Fujimoto (1991) afirmam que a capacidade da manufatura é um fator muito importante para assegurar um rápido ciclo de protótipos, rápidos tempos de desenvolvimento e lotes pilotos e ramp-ups efetivos. A empresa que conseguir fazer protótipos mais rápidos estará apta a perceber e resolver problemas mais rápido e antes do lote piloto e do ramp-up. Se a organização da manufatura é flexivel e efetiva e pode resolver esses problemas rápidamente, o ramp-up será mais rápido e a qualidade dos produtos no mercado maior. A Tabela 1 mostra as características e paradigmas das fabricações de protótipos no Japão, EUA e Europa; Para medir o efeito da capacidade da manufatura na qualidade do projeto, deve-se olhar para a conformidade do projeto no lote piloto e para a taxa de aprendizado no lote piloto e no ramp-up.

As empresas japonesas têm tempos de protótipos menores, mas eles levam o mesmo período de tempo para completar o processo de engenharia. $O$ fim do processo é marcado por acertos finais. E não significa necessariamente que todas as ferramentas e tempos estão completos. Clark e Fujimoto (1991) sugerem que nas empresas americanas os lotes piloto começam com partes produzidas por ferramentas e equipamentos que são também protótipos. Além disso, um grande número de mudanças de engenharia ocorre depois do lote piloto e mesmo depois que o ramp-up começa. Assim engenharia de produto e de processo nas empresas americanas e européias acabam ocorrendo fases finais do PDP, como na corrida do lote piloto e no ramp-up, apesar de o projeto ter sido formalmente liberado.

Mesmo nas melhores circunstâncias, o início da manufatura do produto é geralmente um período de confusão, afirmam Clark e Fujimoto (1991): variação da produtividade, taxa de defeitos, retrabalhos, máquinas quebrando, linhas parando, e engenheiros e supervisores correndo para resolver problemas. Quanto mais rápido o ramp-up, maior confusão nas linhas de produção, assim como as condições de operação e as atribuições das tarefas mudam diariamente. À luz da relação entre velocidade do ramp-up e o nível de confusão no chão-de-fábrica, a performance dos projetos japoneses é notavel, como podemos ver na Figura 2, que compara tempo de alcançar produção total e a taxa média da aceleração da produção por todo o ramp-up. 


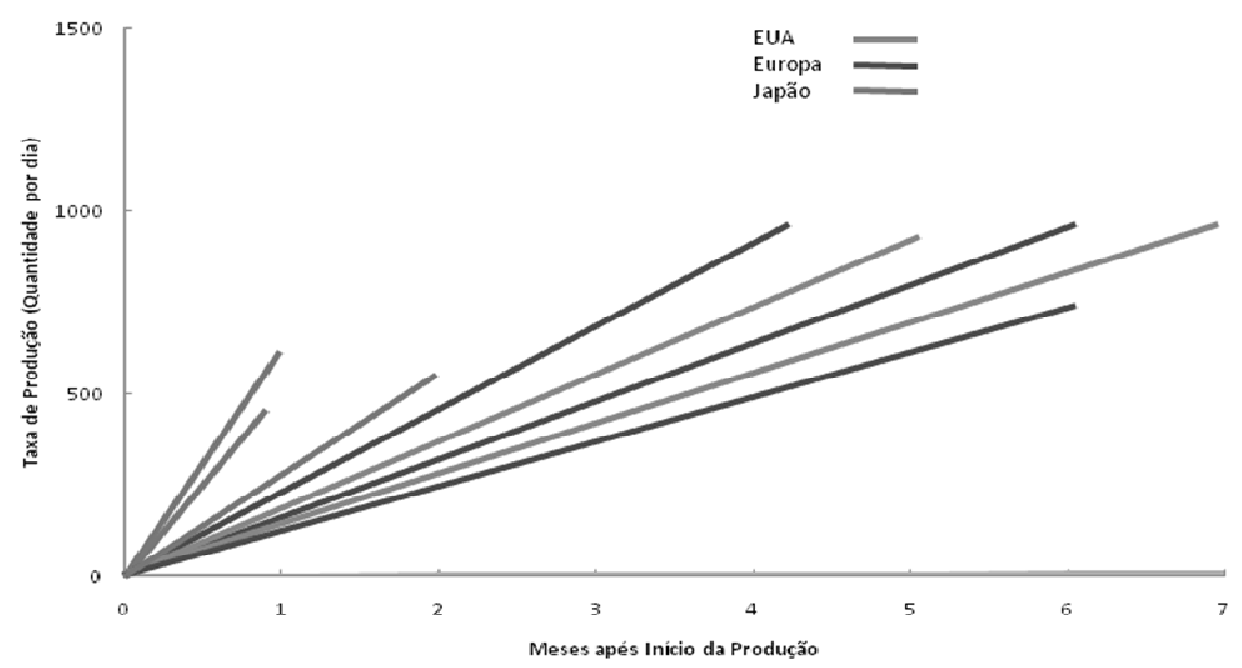

Figura 2 - Comparação entre os ritmos de ramp-up. Adaptado de Clark \& Fujimoto (1991)

A desordem nos projetos japoneses, que tendem a ser mais rápidos, é maior. Comparado a um nível normal de performance, projetos japoneses sofreram um crescimento agudo em defeitos por hora e por unidade no início do ramp-up e depois alcançaram o desempenho-alvo rapidamente. EUA e Europa experimentaram menor desvio da performance normal, mas são muito mais lentos para alcançar níveis alvos de produtividade. Esta configuração pode ser visualizada na Figura 3 a seguir.

Como são requeridas grandes habilidades para operações normais, produtividade e qualidade na montagem dos projetos japoneses tendem a ser mais sensíveis a perturbações. Mas apesar de altas habilidades requeridas e um rápido ramp-up - os dois impedimentos para recuperação da qualidade e da produtividade - projetos japoneses retornam rapidamente ao normal. Esta é particularmente verdade para os defeitos na montagem, com a operação normal sendo restaurada em aproximadamente um mês.

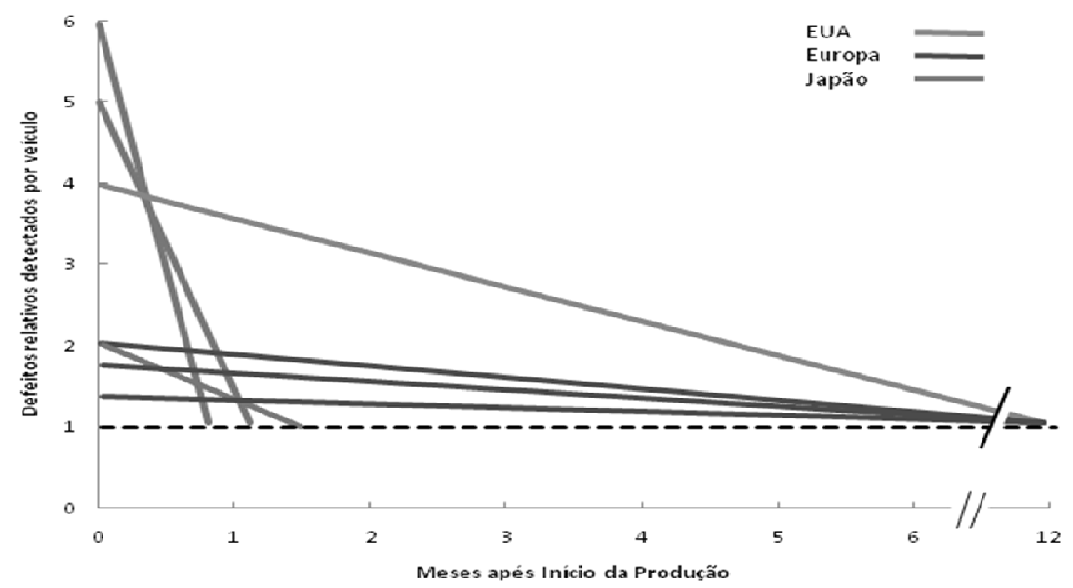

Figura 3 - Quantidade de defeitos. Adaptado de Clark \& Fujimoto (1991) 
O rápido aprendizado organizacional durante o ramp-up nas montagens japonesas é enraizado na comunicação em tempo real, na continuidade do sistema de produção originalmente utilizado para os modelos mais antigos, na exposição do novo produto à linha de produção, e na habilidade para a solução de problemas no chão de fábrica. Nota-se que o aprendizado japonês se dá ao rodar lotes pilotos na montagem e ao enfatizar os novos modelos. Todos os defeitos são notificados a todo o chão de fábrica assim que detectados, e resolvidos pelos supervisores no chão de fábrica mesmo, e não pelos engenheiros, o que aumentaria os tempos para a resolução do problema. O que se passa na solução de problemas no ramp-up no chão de fábrica não é o tradicional trabalho realizado pela qualidade (não é um departamento mas sim uma atividade realizada, tipo melhoria continua). Estes funcionam bem na continuidade da produção, mas são muito lentos para tomar decisões em "tempos de guerra". O método de guerra dos japoneses envolve supervisores experientes que dirigem as atividades, implantam linhas técnicas e resolvem problemas hora após hora, contrastando com o padrão ocidental, que se utiliza dos engenheiros.

Assim Clark e Fujimoto (1991) concluem que excelência na atividade da manufatura é um importante ingrediente para o sucesso do PDP. E afirmam ainda que rápidos ciclos de protótipos e manufatura geram vantagens na qualidade do projeto, e que seu efetivo controle diminui custos, assim como possibilita intercambiar a linha de produção entre modelos novos e antigos e fazer o ramp-up ser mais rápido.

\section{ESTUDO DE CASO EM RAMP-UP DE NOVOS PRODUTOS}

\subsection{Caracterização da empresa}

A empresa na qual foi estudado o ramp-up de produtos de alta tecnologia foi fundada em 1985 por professores e técnicos de uma das Universidades da cidade na qual se localiza. Iniciou suas atividades com a produção de filmes finos especiais e aplicações industriais a laser. Posteriormente, a empresa entrou nos mercados de defesa, médico-oftálmico e espacial. Suas unidades de negócio são basicamente: tratamento de lentes oftálmicas com aplicação de filmes anti-risco e anti-reflexo; produção de lentes sob encomenda para aplicação industrial; medidores a laser para controle de pneus e multiposicionador laser; microscópios cirúrgicos oftálmico e odontológico, retinógrafos digitais e lasers fotocoaguladores para cirurgia de retina; componentes ópticos e sistemas de detecção a laser para a aeronáutica e o exército brasileiros; e produtos da área espacial, como subsistemas para integração em satélites de monitoramento ambiental que realizam a captação e o processamento de imagens da Terra.

A empresa compõe-se de quatro diretorias: filmes finos, pesquisa e desenvolvimento, diretoria comercial e diretoria de manufatura. Cada diretoria tem como diretor um dos sócios proprietários da firma. A diretoria de "pesquisa e desenvolvimento" (P\&D) é responsável pelo projeto dos equipamentos, que podem ser médicos, aeroespaciais ou militares. Ela é composta de um grupo de engenharia formado por engenheiros mecânicos, eletrônicos, de software e físicos e por um grupo de montagem especializada, composto por técnicos em eletrônica e mecânica, responsável pela integração dos equipamentos de defesa desenvolvidos 
e montagem dos protótipos de equipamentos em desenvolvimento. Ela utiliza serviços especializados das áreas de filmes finos e de operações industriais.

Os produtos sobre os quais foi realizado o acompanhamento do ramp-up de produção foram desenvolvidos pelo departamento de P\&D da empresa, sendo todos relacionados à área de equipamentos médicos. Nas etapas próximas à transferência do produto para a linha de produção, departamentos vinculados às diretorias de pesquisa e desenvolvimento, de filmes finos, comercial e de manufatura participaram das atividades de ramp-up do produto, as quais consistiram basicamente de: fabricação de lote piloto; desenvolvimento de material promocional e atividades de marketing de lançamento; documentação e submissão do produto a registros necessários a sua comercialização; refinamento da engenharia de processos relacionada ao produto; refinamento das subcontratações e parcerias com terceiros; atividades de montagem, integração e teste do lote piloto; e levantamento das necessidades de alterações do produto geradas pelos clientes finais e pelos departamentos envolvidos no ramp-up.

O produto A é um equipamento cujo objetivo é fotografar a retina de um paciente para detectar possíveis lesões que possam implicar em grave prejuízo ou perda da visão. O sistema consiste em uma unidade de captura de imagem na qual há uma complexa óptica de iluminação do olho e captação do reflexo do feixe projetado na retina do paciente. O sinal de luz captado é convertido em pulsos elétricos através de um sensor charge-coupled device (CCD) e transformado em imagem digital em uma câmera de 4.0 Megapixels. A imagem é transmitida para um computador equipado com um software de processamento de imagens e um banco de dados para o armazenamento de informações geradas nos exames, tais como nome do médico, do paciente, data e diagnóstico. As imagens podem ser apresentadas aos pacientes através do monitor do computador ou de impressões de qualidade fotográfica.

O produto B é um equipamento que gera pulsos laser de até 2500 miliwatts $(\mathrm{mW})$ de potência durante um certo intervalo de tempo. Os pulsos objetivam coagular lesões da retina e reduzir a possibilidade de espalhamento que aumente 0 prejuízo à visão do paciente. A aplicação dos pulsos laser é considerada invasiva ao paciente e com alto grau de risco à visão. Isso faz com que os requisitos normativos aplicáveis a esse produto sejam bastante rigorosos. O produto $\mathrm{C}$ é um equipamento que auxilia no exame de acuidade visual, sendo composto de um software que reúne inúmeros testes que são utilizados por todos os oftalmologistas, entre eles o astigmatismo, o daltonismo, a miopia, etc. Os produtos D e E são semelhantes ao produto $B$, sendo uma evolução tecnológica que utiliza a frequência visível do verde e do amarelo (respectivamente). Dessa forma, o corpo do paciente absorve mais potência e conseqüentemente sente menos dor durante os procedimentos cirúrgicos. O produto $\mathrm{F}$ é um equipamento para tratamento de cerotocone, que utiliza led ultravioleta de potência controlada. Ele possui parâmetros de tratamento que o médico ajusta de acordo com a necessidade do paciente. A partir da injeção de riboflavina no olho do paciente, o laser do equipamento excita esse composto químico formando cadeias que ajudam no tratamento dessa anomalia. 


\subsection{Ramp-up dos projetos}

O sistema de gestão de configurações da empresa aplicado ao PDP prevê que ao longo do ramp-up sejam estabelecidos indicadores de desempenho que permitam identificar as curvas de ramp-up relacionadas ao número de alterações realizadas nos equipamentos, de maneira similar ao gráfico apresentado na Figura 3: quantidade de defeitos. Tal sistemática é considerada mais apropriada ao baixo volume de produção que caracteriza a empresa.

Os gráficos ilustrados a seguir apresentam a evolução das alterações de projeto realizadas na empresa ao longo do tempo, a partir da implantação do sistema de Gestão das Configurações. Os gráficos apresentam o número de alterações realizadas mensalmente e uma linha de tendência logarítmica, de forma a evidenciar o crescimento ou decrescimento do número de alterações durante o período de ramp-up. Espera-se, a princípio, que as curvas de ramp-up se comportem segundo estabelece a teoria, conforme perfis ilustrados na figura 3 . Considerando-se ainda que não haverá "zero alteração", sendo a curva uma assintética.

É interessante explicar o fato de ter sido escolhido demonstrar a evolução das alterações nos doze primeiros meses, para que se tivesse um período padrão de forma a indicar uma tendência deste número de alterações.

$\mathrm{Na}$ Figura 4 é possível observar que o lançamento do produto $A$ se deu no início de 2008, e as mudanças observadas já eram esperadas devido à complexidade do produto. Pode-se perceber a tendência de diminuição das alterações realizadas, o que aponta para que as mudanças realizadas anteriormente foram eficazes e que nenhuma evolução tecnológica ocorreu no período, o que desencadearia muitas mudanças.

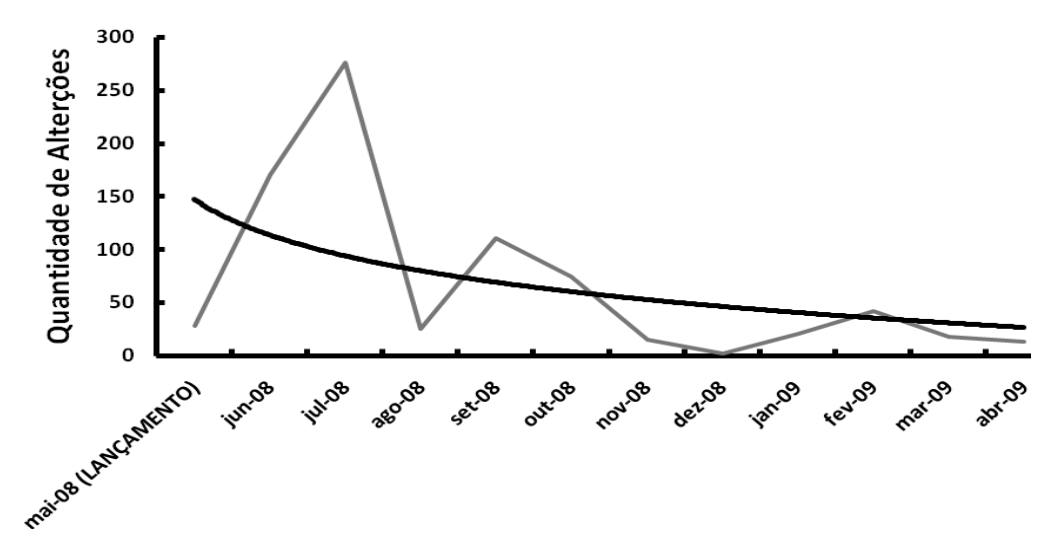

Figura 4 - Produto A. Fonte: Dados da empresa

As curvas referentes ao produto B estão apresentadas na Figura 5, cujo lançamento ocorre no final de 2007, com uma leve tendência de aumento no número de alterações no início do projeto. 


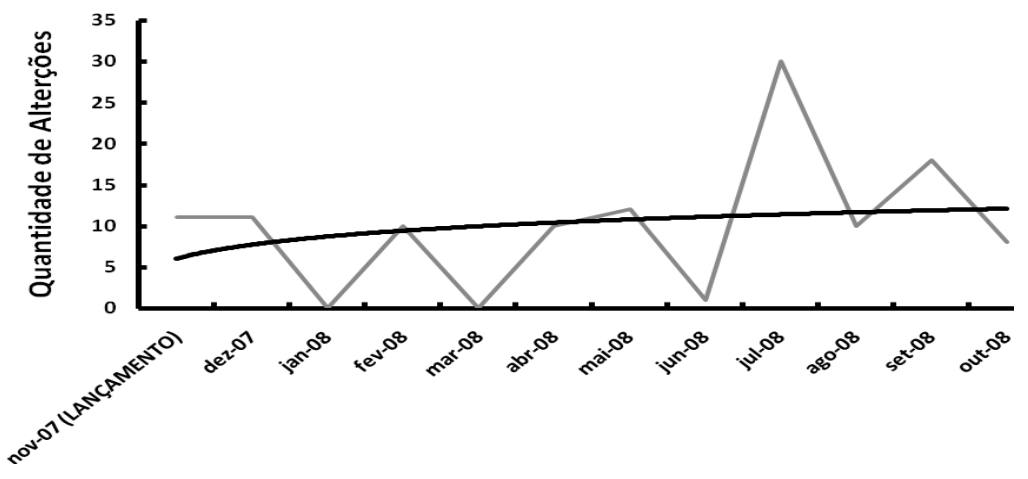

Figura 5 - Produto B. Fonte: Dados da empresa.

Na Figura 6 encontram-se as curvas referentes ao produto C. Seu lançamento se deu em novembro de 2008, e apresentou em seguida um declínio no número de alterações de projeto.

Na Figura 7 abaixo é possível observar os dados referentes ao equipamento D. O equipamento foi lançado em agosto de 2008, e pode-se perceber uma diminuição do número de alteração nos primeiros meses, porém com um pico de alteração no penúltimo mês da análise.

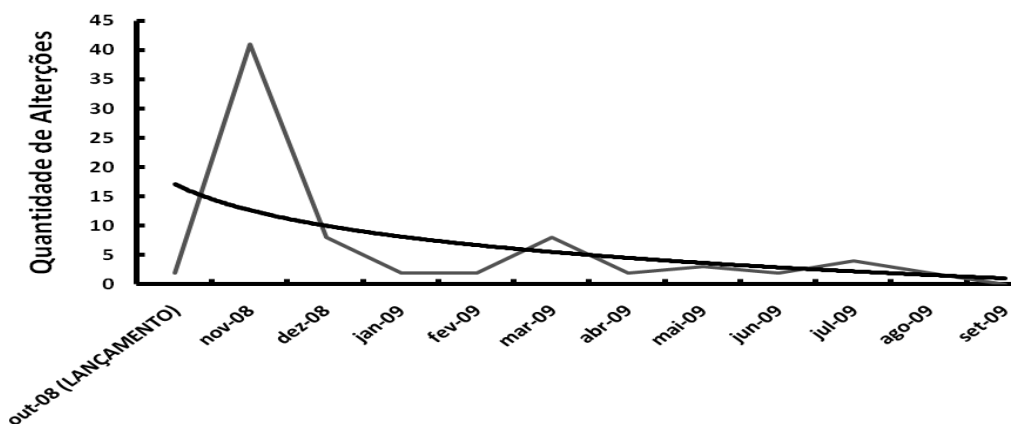

Figura 6 - Produto C. Fonte: Dados da empresa.

A Figura 8 representa as curvas do equipamento E. É um dos equipamentos mais recentes da empresa, lançado em agosto de 2010. Essa curva apresenta apenas nove meses de análise, pois até a conclusão deste artigo, os dados do mês de maio/2011 ainda não haviam sido computados. 


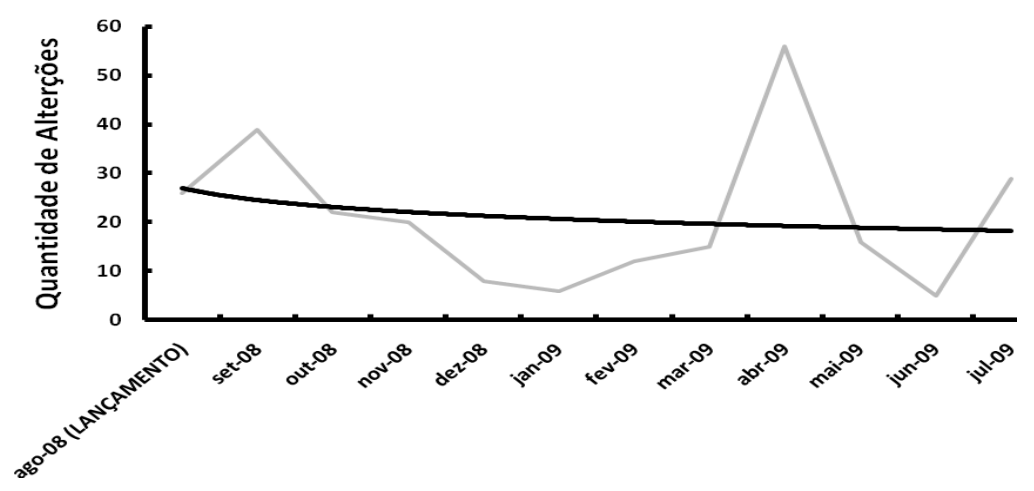

Figura 7 - Produto D. Fonte: Dados da empresa.

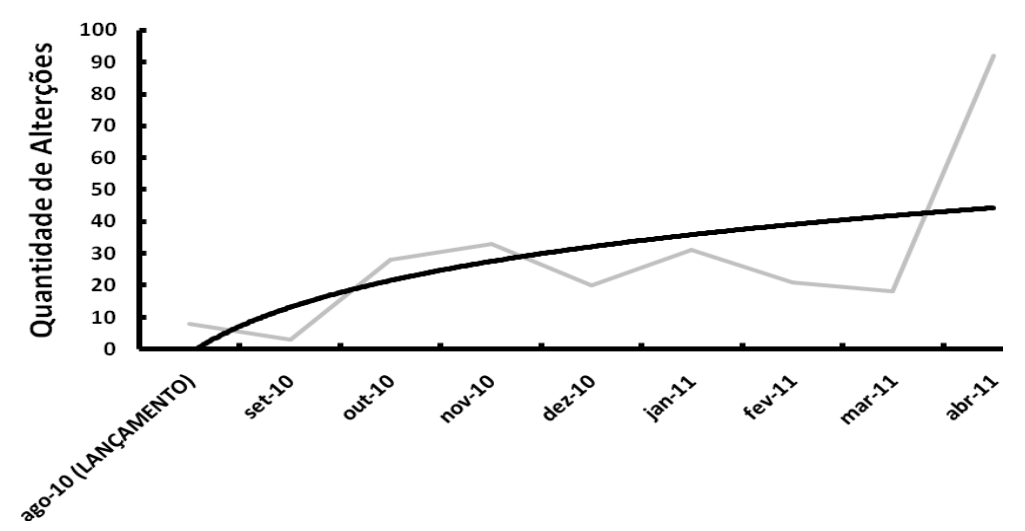

Figura 8 - Produto E. Fonte: Dados da empresa.

Na Figura 9 pode-se observar os dados referentes ao produto $\mathrm{F}$, lançado em outubro de 2008. Percebe-se um grande pico de alterações no quarto mês do lançamento do produto, com uma queda do número de alterações após este período.

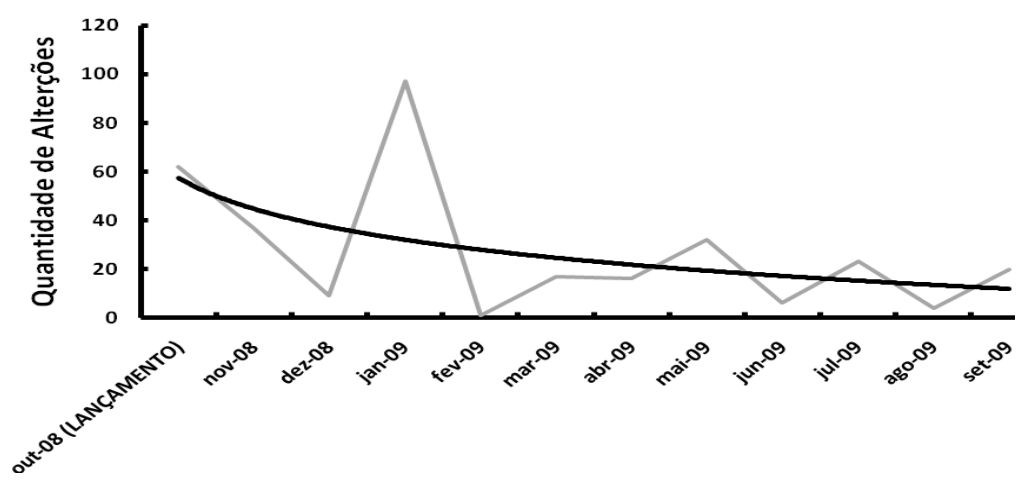

Figura 9 - Produto F. Fonte: Dados da empresa. 


\subsection{Análise do ramp-up dos projetos}

Analisando a curva do produto A nota-se que é o equipamento que apresenta o maior número de alterações. Isto se deve em parte a sua complexidade pois é composto por um número muito maior de componentes. E também devido a ser um dos projetos mais antigos que tem um controle efetivo das alterações. Mas o que deve ser ressaltado é que apresentou uma tendência de diminuição do número de alterações, e menores números de alterações sugerem melhoria constante e resultado da experiência acumulada. Ou mesmo devido ao não surgimento de uma nova tecnologia que substituiria a utilizada no projeto.

Ao observar a curva do produto $B$ podemos perceber que ao longo do tempo este passou a receber algumas configurações diferentes das iniciais, pois o requerido dos equipamentos de alguma forma se apresentou diferente do projeto inicial, sendo que isso pode ser explicado pelas pesquisas da área médica que acabam utilizando o equipamento de maneira diferente do planejado ou a novas formas de tratamento que são estudadas diariamente. Em 2007 houve o desenvolvimento de um protocolo diferenciado de tratamento, e por uma decisão estratégica a empresa decidiu lançar esta configuração em um novo console (aspectos de design diferentes) e aproveitando a oportunidade foi realizada uma alteração na eletrônica do equipamento para deixá-lo mais robusto. Essas alterações culminam no inicio de $2008 \mathrm{com}$ a validação desta configuração. Houve ainda em 2008 a tentativa de validação de outra configuração, mas como esta não foi aceita pelo meio médico, foi colocada de lado.

Observando a curva do produto $\mathrm{C}$ percebemos um grande número de alterações apenas no primeiro mês após o lançamento do produto, com uma rápida diminuição dessas alterações que tenderam a ficar constantes em um número muito baixo. Isso pode ser explicado pela baixa complexidade do equipamento e não surgimento, no período, de uma atualização que substituísse o equipamento antigo.

A validação do projeto do produto D ocorreu em agosto de 2008. Desde então o setor de projeto vem trabalhando em melhorias de produto, buscando maior robustez e controle. $O$ produto enfrentou algumas dificuldades técnicas depois do lançamento, o que motivou algumas das alterações consideradas críticas, como pode-se perceber no nono mês da análise. O mesmo ocorreu com o equipamento $E$, com seu lançamento em agosto de 2010. O mesmo teve um grande aumento de modificações após nove meses do lançamento.

$\mathrm{O}$ equipamento $\mathrm{F}$ apresentou um comportamento diferente quando comparado aos outros equipamentos analisados. Uma possível explicação pode ser o fato de que é comum nestes equipamentos eletro-médico ocorrerem alterações de software após a validação para sanar pedidos de clientes, e isso aconteceu bastante com o produto. No final de 2008 e início de 2009 foi desenvolvida uma alternativa de aquisição de um componente crítico do equipamento visando a não dependência de um único fornecedor. 


\section{CONCLUSÃO}

Este trabalho procurou apresentar as curvas de ramp-up de produtos obtidas a partir do controle sistemático de alterações, tratado até aqui como Gestão das Configurações. A adoção destas práticas é ainda pouco explorada na literatura e a intenção deste trabalho é contribuir com esta base de conhecimento. É possível inferir que a partir do momento que são medidas as mudanças de engenharia as pessoas se tornam mais responsáveis por estas mudanças e passam a avaliar melhor as necessidades e os impactos destas alterações tanto para os produtos quanto para os processos de manufatura e apoio. O número de alterações nos produtos tende a cair com o avanço do tempo, afinal é possível aprender com o passado e com as experiências vividas, mesmo que neste caminho ocorram alguns problemas e necessidades de grandes alterações nos produtos.

Nos produtos apresentados podemos perceber essa tendência, conforme a teoria, em alguns produtos. Porém em outros, não ocorre tal tendência. Tal fato pode ser explicado devido a alguns problemas críticos em projetos, que ocorreram dentro do intervalo de tempo estudado.

Hoje a GC se mostra uma aliada no desenvolvimento de novos produtos e na manutenção tanto da configuração como do histórico dos produtos desenvolvidos pela empresa, pois torna possível visualizar o projeto como um todo, permitindo realizar mudanças de estratégias com vistas ao aprimoramento dos equipamentos produzidos.

A GC leva também a um aumento da eficiência das alterações, uma vez que estas não são implementadas somente se uma análise crítica da sua real necessidade for feita. Com isso alterações sem critério são evitadas, o que afetaria negativamente a competitividade da empresa.

\section{REFERÊNCIAS}

AKAMPHON, S. Enabling Effective Product Launch Decisions. PhD. Thesis, Department of Mechanical Engineering, MIT, 2008.

BARBALHO, S. C. M. Modelo de referência para o desenvolvimento de produtos mecatrônicos: proposta e aplicações. Tese de Doutorado, Departamento de Engenharia de Produção, EESC/USP, 2006.

CARRILO, J. E.; FRANZA, R. M. Investing in product development and production capabilities: The crucial linkage between time-to-market and ramp-up time. European Journal of Operational Research, 171, p. 536-556, 2006.

CLARCK, K. B.; FUJIMOTO, T. Product Development Performance: strategy, organization, and management in the world auto industry. Boston: Harvard Business School Press, 1991.

HALLER, M.; PEIKERT, A.; THOMA, J. Cycle time management during production ramp-up. Robotics and Computer Integrated Manufacturing, v. 19, p. 183-188, 2003. 
NONAKA, I.; TAKEUSCHI, I. Criação de conhecimento na empresa. Trad. Ana Beatriz Rodrigues, Priscilla Martins Celeste. Rio de Janeiro: Campus, 1997.

PROJECT MANAGEMENT INSTITUTE (PMI). Project Management Body of Knowledge - PMBOK (Tradução Livre), Capítulo de Minas Gerais do PMI, 2005.

ROZENFELD, H.; FORCELLINI, F. A.; AMARAL, D. C.; DE TOLEDO, J. C. ; DA SILVA, S. L. da; ALLIPRADINI, D. H.; SCALICE, R. K. Gestão de Desenvolvimento de Produtos. São Paulo: Editora Saraiva, 2006.

SAMARAS, T.; CZERWINSKI, S. Fundamentals of configuration management. New York: Prendice-Hall,1971.

SANTOS JÚNIOR, D. Estratégia tecnológica e definição de produtos. Dissertação de Mestrado, Departamento de Engenharia de Produção, UFSCar, 1997.

THIOLENT, M. Metodologia da pesquisa-ação. São Paulo: Editora Cortez, 2006.

WATTS, F. B. Engineering documentation control handbook. 2.ed. New Jersey: Noyes Publications, 2000. 